\title{
Y-box binding protein 1 acts as a negative regulator of stearoyl CoA desaturase 1 in clear cell renal cell carcinoma
}

\author{
ERIC JEFFORDS $^{1 *}$, SAMUEL FREEMAN $^{2 *}$, BREANNA COLE $^{1}$, KATE ROOT $^{2}$, THIERRY CHEKOUO $^{3}$, \\ RICHARD G. MELVIN ${ }^{2}$, LYNNE BEMIS ${ }^{2}$ and GLENN E. SIMMONS JR ${ }^{2,4}$ \\ ${ }^{1}$ Department of Biology, The College of St. Scholastica, Duluth, MN 55811; ${ }^{2}$ Department of Biomedical Sciences, \\ University of Minnesota Medical School, Duluth, MN 55812, USA; ${ }^{3}$ Department of Mathematics and Statistics, \\ University of Calgary, Calgary, AB T2N1N4, Canada; ${ }^{4}$ Carcinogenesis and Chemoprevention Program, \\ Masonic Cancer Center, Minneapolis, MN 55455, USA
}

Received January 17, 2020; Accepted August 4, 2020

DOI: $10.3892 / \mathrm{ol} .2020 .12026$

\begin{abstract}
Y-box binding protein 1 (YB-1) is a regulatory protein associated with oncogenesis and poor prognosis in patients with cancer. In the cell, YB-1 functions as a DNA and RNA binding protein that promotes or suppresses expression of target genes. The cancer-promoting activity of YB-1 is mediated through its activation of oncogenes and repression of tumor suppressor genes. Lipogenic enzyme stearoyl-CoA desaturase (SCD1) drives the production of endogenous monounsaturated fatty acids (MUFAs) in cells and protects against toxic buildup of saturated fatty acids. Clear cell renal cell carcinoma (ccRCC) is often characterized by aberrantly high SCD1 expression and cytosolic accumulation of unsaturated fatty acids. In the present study, a proteomics screen of cells treated with inhibitors of SCD1 supported a potential relationship between YB-1 and SCD1. It was revealed that the presence of MUFAs led to increased protein synthesis and increased expression of high molecular weight forms of YB-1 in ccRCC cells, but not in non-tumorigenic cells. Ectopic expression of YB-1 led to decreased expression levels of SCD1 protein and mRNA in ccRCC cell lines. Conversely, targeted knockdown of YB-1 increased SCD1 mRNA abundance. Analysis of ccRCC patient data from The Cancer Proteome Atlas database showed YB-1 expression was negatively associated with survival, whereas SCD1 was associated with improved survival. These data suggested an antagonistic relationship between YB-1 and SCD1 that may influence survival of patients with ccRCC.
\end{abstract}

Correspondence to: Dr Glenn E. Simmons Jr, Department of Biomedical Sciences, University of Minnesota Medical School, 1035 University Drive, Duluth, MN 55812, USA

E-mail: gsimmons@d.umn.edu

Key words: Y-box binding protein 1, clear cell renal cell carcinoma, stearoyl-CoA desaturase, monounsaturated fatty acids, cancer, lipid metabolism, The Cancer Genome Atlas, kidney

\section{Introduction}

Clear cell renal cell carcinoma (ccRCC) is the most common form of renal malignancy $(1,2)$. Yet, the contribution of the characteristically elevated monounsaturated fatty acids (MUFAs) to the establishment of ccRCC remains incompletely understood (3-5). It has been hypothesized that the elevated unsaturated fatty acid content of ccRCC cells is responsible for their varied response to drug therapies (6). MUFAs are produced by the enzyme stearoyl-CoA desaturase (SCD1), a protein often highly expressed in tumors (7-9). Previous studies describe unsaturated fatty acid as a stabilizer of oncogenes that function to promote cell growth and inhibit apoptosis (10-14). This suggests that the presence of unsaturated lipids in ccRCC is necessary for growth and survival (15-21). However, there is growing evidence that demonstrates a positive correlation between MUFAs and survival in various model systems (22-25). SCD1-derived MUFAs play an important protective role in normal and transformed cells by preventing the toxic accumulation of saturated fatty acids resulting from rapid proliferation $(26,27)$. The unsaturated lipids made by SCD1 are critical to membrane synthesis, signal transduction, and energy storage (13). Targeting SCD1 activity has been suggested as a viable strategy to combat tumor development $(9,12,28)$. However, blocking fatty acid desaturation creates an imbalance in the ratio of saturated to unsaturated fat, leading to a cellular stress response that includes inhibition of global mRNA translation, and ultimately death in both normal and transformed cells $(29,30)$. Therefore, despite the therapeutic potential, the relationship between SCD1 and organismal longevity, makes SCD1 a precarious drug target (22-25).

Y-box binding protein 1 (YB-1) is a phylogenetically conserved DNA and RNA binding protein that controls expression and translation of numerous genes (31). YB-1 is regulated both spatially and through posttranslational modifications. In the cytoplasm YB-1 represses the translation of mRNAs into proteins that are involved in survival and proliferation $(32,33)$. The ability of YB-1 to repress target transcripts is regulated, in part, by tissue transglutaminase (TG2). TG2 crosslinks YB-1 into detergent-resistant oligomers, containing two or 
more YB-1 monomers, in a calcium-dependent manner (34). Furthermore, transforming growth factor (TGF- $\beta$ ) also stimulates YB-1 oligomer formation, which leads to de-repression of smooth muscle actin (acta2) (35). Under certain stress conditions, YB-1 is phosphorylated and translocated to the nucleus as a transcription factor for genes that promote growth, drug resistance, and cell survival $(36,37)$.

YB-1 is considered an oncogene because it is overexpressed in many cancers and is highly correlated with metastatic potential and patient mortality (38). While YB-1 regulates the expression of a diverse group of target genes, there is no true consensus on how YB-1 identifies its targets (39-41). We hypothesized that SCD1 is negatively regulated by YB-1 in ccRCC. The present study provides evidence of a previously unknown relationship between YB-1 and SCD1 gene expression using a combination of proteomics, bioinformatics, and molecular methods. Our data suggests a dynamic interplay between unsaturated fatty acid levels and oncogenic capacity, and highlights a relationship between protein expression and lipid levels that could have significant impact on overall survival in renal cancer patients.

\section{Materials and methods}

Materials. We obtained fatty acids (FAs) from Nu-Chek Prep, Inc.; radiolabeled S-35 methionine from Perkin-Elmer (cat. no. NEG709A500UC); SCD1 inhibitor (A939572; cat. no. 19123), Nonidet P-40 (NP-40; cat. no. 600009) and Protein Synthesis kit (cat. no. 601100) from Cayman Chemicals; rabbit anti-YB-1 from ProteinTech; mouse anti- $\beta$-actin from Millipore Sigma; rabbit anti-SCD1 from Cell Signal; YB-1-myc plasmid from Addgene; non-targeting control siRNA and YB-1 siRNAs from Qiagen; FA-free BSA from Sigma-Aldrich; Protease inhibitor cocktail from Roche; Fetal Calf serum (FCS) and Delipidated fetal calf serum (DFCS) from Gemini Bio. All FAs added into culture media were conjugated to BSA as previously reported (10).

Cell lines. ccRCC cells 786-O and SW156 were obtained from ATCC. Non-tumorigenic SV589 human fibroblasts were from the UT Southwestern Department of Molecular Tissue Culture Core Facility. SV589 cells were grown in Dulbecco's modified Eagle's medium (DMEM) with $1.0 \mathrm{~g} / \mathrm{l}$ glucose, 100 units $/ \mathrm{ml}$ penicillin and $100 \mu \mathrm{g} / \mathrm{ml}$ streptomycin supplemented with 5\% FCS (complete DMEM). SW156 and 786-O cells were grown in DMEM with $4.5 \mathrm{~g} / 1$ glucose (DMEM-HG), 100 units/ml penicillin, and $100 \mu \mathrm{g} / \mathrm{ml}$ streptomycin supplemented with 5\% FCS (complete DMEM-HG). Except for SV589 cells that were incubated in $8.8 \% \mathrm{CO}_{2}$, all cells were maintained at $37^{\circ} \mathrm{C}$ in $5 \% \mathrm{CO}_{2}$.

Lipid deprivation. Cells were plated in complete DMEM-HG at appropriate cell density for specific experimental conditions overnight. The following day, all culture media was removed and cells were rinsed one time with sterile phosphate buffered saline. Cells were replenished with delipidation media consisting of DMEM-HG supplemented with 100 units $/ \mathrm{ml}$ penicillin, and $100 \mu \mathrm{g} / \mathrm{ml}$ streptomycin with $5 \%$ delipidated fetal calf serum (DFCS), and $1 \mu \mathrm{M}$ SCD-1 inhibitor (A939572, Cayman Chemicals). Cells were incubated in delipidation media overnight and assayed for response to lipids the following day.

Cell harvest and lysis. Cells were harvested by scraping the cells and media into conical tubes and placing on ice. Following harvest, the cell suspensions were spun down at room temperature for $5 \mathrm{~min}$ at $800 \mathrm{x} \mathrm{g}$. The supernatant was aspirated, and the cells were washed twice with PBS. Cells were then lysed with $100 \mu \mathrm{l}$ of seize 2 lysis buffer (25 mM Tris-HCl pH 7.2, $0.15 \mathrm{M}$ $\mathrm{NaCl}, 5 \mu \mathrm{g} / \mathrm{ml}$ pepstatin, $10 \mu \mathrm{g} / \mathrm{ml}$ leupeptin, $2 \mu \mathrm{g} / \mathrm{ml}$ aprotinin, $2 \mu \mathrm{g} / \mathrm{ml} \mathrm{N}$-[N-(N-Acetyl-L-leucyl)-L-leucyl]-L-norleucine, $1 \%$ NP-40). The lysate was passed through a $22 \mathrm{G}$ needle 10 times while on ice followed by rotation at $4^{\circ} \mathrm{C}$ for $15 \mathrm{~min}$. The lysate was pelleted at $21,000 \mathrm{x} \mathrm{g}$ for $10 \mathrm{~min}$ and the supernatant was collected. Protein concentrations were found using the BCA Gold Protein Assay kit (Thermo Fisher Scientific) and read at $490 \mathrm{~nm}$. Sample lysate was mixed with loading buffer and then boiled for $5 \mathrm{~min}$, and loaded onto 10\% SDS-PAGE gel at 10 or $20 \mu \mathrm{g}$ total protein per well.

Stable isotope labeling of amino acids in cell culture (SILAC). Incorporation of amino acids into newly synthesized proteins in the presence of unsaturated fatty acid was measured in SW156 ccRCC cells. In brief, 150,000 cells were plated in $100 \mathrm{~mm}$ dishes in complete DMEM (DMEM with $4.5 \mathrm{~g} / 1$ glucose, 100 units $/ \mathrm{ml}$ penicillin, and $100 \mu \mathrm{g} / \mathrm{ml}$ streptomycin supplemented with $5 \%$ FCS) in duplicate overnight. The following day, plates were divided equally and given either complete DMEM, 10\% Delipidated FCS (DFCS) with heavy isotope of Arginine/Lysine (Heavy Medium) or complete DMEM, 10\% DFCS with light isotope of Arginine/Lysine (Light Medium) for $24 \mathrm{~h}$. The next day, $100 \mu \mathrm{M}$ oleate-BSA was added to cells in Heavy Medium, and $100 \mu \mathrm{M}$ BSA alone was added to cell in Light Medium and incubated for $6 \mathrm{~h}$ at $37^{\circ} \mathrm{C}$. Total protein was harvested using seize 2 lysis buffer + protease inhibitors. For each treatment $100 \mu \mathrm{g}$ of protein was loaded onto $16.5 \%$ Tris-Tricine BioRad precast gel (Bio-Rad, cat. no. 3450064). Gel was run only long enough to allow protein to enter resolving portion. Gel was stained with Gel-Code Blue (ThermoFisher, cat. no. 24590), and protein band was excised with ethanol-cleaned razor and diced into $10 \mathrm{~mm}^{2}$ fragments. Protein bands were sent to UT Southwestern Proteomics core facility for protein identification using a short reverse-phase Liquid Chromatography tandem mass spectrometry method.

Protein synthesis. Protein synthesis was measured by radiolabeled-methionine (S-35) incorporation into SV589 and SW156 ccRCC cells. In brief, 150,000 cells were plated in $60 \mathrm{~mm}$ dishes overnight. The following day cells were treated with delipidation media, DMEM $+5 \%$ delipidated FCS (DFCS) $+1 \mu \mathrm{M}$ A939572 (SCD1 inhibitor), overnight at $37^{\circ} \mathrm{C}$. The following morning cells were treated with $100 \mu \mathrm{M}$ oleate-BSA or equivalent volume of $10 \% \mathrm{BSA}$ for $4 \mathrm{~h}$. Following 4-h incubation with fatty acid, cells were pulsed with $150 \mu \mathrm{Ci} / \mathrm{ml} \mathrm{S}-35$ methionine media for $1 \mathrm{~h}$ at $37^{\circ} \mathrm{C}$. After pulse, cells were washed and lysed with seize 2 lysis buffer + protease inhibitors. Protein was quantitated by BCA assay and total protein was normalized across samples before performing trichloroacetic acid (TCA; cat. no. T0699, Sigma) precipitation. TCA was added to lysate at $1 / 4$ volume of total 
lysate and incubated at $4^{\circ} \mathrm{C}$ with agitation for $10 \mathrm{~min}$. Samples were then centrifuged at 20,000 x g for $5 \mathrm{~min}$. Pellets were washed twice in $200 \mu \mathrm{l}$ of cold acetone. Pellets were dried at $95^{\circ} \mathrm{C}$ for $5 \mathrm{~min}$ and rehydrated with $200 \mu \mathrm{l}$ scintillation fluid before transferring to labeled vials with $5 \mathrm{ml}$ of scintillation fluid. Samples were read on Beckman-Coulter Scintillation counter. Protein synthesis in 786-O cells was measured by non-radioactive Protein synthesis kit from Cayman Chemical (cat. no. 601100). In brief, 500,000 cells per well were plated into 96-well black clear bottom plates and incubated at $37^{\circ} \mathrm{C}$ overnight. The following day, cells were kept in complete media or placed in delipidation media overnight. The following day, cells were treated with oleate, arachidonate, palmitate, or cycloheximide as negative control. Protein synthesis assay was conducted per manufacturers instruction and read on a microplate reader at $485 \mathrm{~nm}$ excitation $/ 535 \mathrm{~nm}$ emission.

Proliferation assay. 786-O ccRCC were plated into black clear bottom 96-well plates at 1,000 cells/well in triplicate in complete DMEM (100 units $/ \mathrm{ml}$ penicillin, and $100 \mu \mathrm{g} / \mathrm{ml}$ streptomycin supplemented with $5 \%$ FCS). The following day cell media was exchanged for delipidation media with either $0,10,30$, or $100 \mu \mathrm{M}$ oleate or palmitate. Cells were placed in culture for $48 \mathrm{~h}$. At the end of incubation cell growth was analyzed using Cell Titer-Glo (cat. no. G7570; Promega) according to manufacturer's instructions.

Immunoblot analysis. Following overnight treatment with $0,10,30$ or $100 \mu \mathrm{M}$ oleate or palmitate, 786-O cells were harvested and lysed as previously described. A total of $10 \mu \mathrm{g}$ of protein was then separated by $10 \%$ SDS-PAGE. After gel electrophoresis was completed, the proteins were transferred to a 0.2-micron polyvinylidene difluoride (PVDF) membrane. All immunoblot equipment and reagents used were from Bio-Rad. The membrane was blocked with a 5\% non-fat milk/PBST solution for $30 \mathrm{~min}$. The membrane had anti-YB-1 antibodies (ProteinTech, 1:1,000 dilution) applied and was incubated at $4^{\circ} \mathrm{C}$ overnight. The following day the membrane was washed $3 \mathrm{x}$ with PBST at 5 min per wash. The $5 \%$ non-fat milk/PBST containing HRP-conjugated secondary was added to the membrane (R\&D Systems anti-rabbit at a 1:10,000 dilution). $\beta$-actin was used as the loading control for all immunoblots (primary antibodies: Sigma, 1:2,500 dilution; secondary antibody: R\&D Systems anti-mouse, 1:10,000 dilution). Protein bands were detected by using $1 \mathrm{ml}$ of SuperSignal ECL from Pierce and visualizing band intensity using Li-Cor imaging system.

Plasmid transfection. 786-O cells were seeded in $60 \mathrm{~mm}$ plates then transfected with $1 \mu \mathrm{g}$ of enhanced green fluorescent protein (pEGFP)-YB-1-myc plasmid DNA or pEGFP-C1 plasmid DNA (from the laboratory of Lynne Bemis). In brief, 150,000 cells were plated in $60 \mathrm{~mm}$ dishes the night prior to transfection and placed at $37^{\circ} \mathrm{C}$. Transfection were done using Lipofectamine 2000 transfection reagent (Invitrogen). Each dish was transfected with $1 \mu \mathrm{g}$ of plasmid DNA per manufacturer's instructions. The GFP signal was observed using a CellDrop Automated Fluorescent Cell Counter (DeNovix) to confirm protein expression prior to cell collection. Cells were incubated $24 \mathrm{~h}$ before harvest to analyze protein and mRNA expression.
RNA interference. 150,000 cells were plated in $60 \mathrm{~mm}$ dishes overnight at $37^{\circ} \mathrm{C}$. Following day transfection mixes were made for each experimental permutation. Functionally verified YB-1 (NM_004559) and control non-targeting siRNAs $(20 \mu \mathrm{M})$ (Qiagen, YB-1 cat. no. SI03019191, ID: 1027415; control cat. no. 0001022076, ID: 1022076) were transfected $100 \mathrm{nM}$ per dish. RNAiMax (Invitrogen) was mixed with appropriate volume of OptiMEM (Gibco) and in a separate tube the appropriate amount of each siRNA for experiment setup was added to appropriate volume of OptiMEM (Gibco), mixed and incubated at room temperature for $5 \mathrm{~min}$. The two solutions were combined at equal volume, mixed and incubated at room temperature for $20 \mathrm{~min}$. Plates containing cells, were washed and replenished with $1.6 \mathrm{ml}$ of OptiMEM, and placed back at $37^{\circ} \mathrm{C}$ until transfection complexes were ready. Then $400 \mu \mathrm{l}$ of transfection mix was added to each dish, and incubated at $37^{\circ} \mathrm{C}$ for $4 \mathrm{~h}$, at which cells would be washed once with complete media and $4 \mathrm{ml}$ of complete media would be added to cells. Cells then incubated at $37^{\circ} \mathrm{C}$ for $48 \mathrm{~h}$.

Chromatin immunoprecipitation assay. 786-O cells were grown to confluence in $10 \mathrm{~cm}$ dishes; a final cell count of approximately $1 \times 10^{6}$ cells/plate. Proteins were cross-linked to DNA using formaldehyde added directly to the culture medium at a final concentration of $1 \%$ for $10 \mathrm{~min}$ at room temperature. The cross-linking reaction was quenched by adding glycine to a final concentration of $0.125 \mathrm{M}$ for $5 \mathrm{~min}$ at room temperature. The medium was then removed and cells were washed with 1X PBS containing a protease inhibitor cocktail. Then cells were scraped, pelleted and washed twice with PBS plus protease inhibitor cocktail as described above. Cells were resuspended in SDS Lysis Buffer (20-163; Millipore) plus protease inhibitor cocktail. Cells were sonicated in a Diagenode Bioruptor sonicator for 30 cycles of sonication (30 sec pulses and $30 \mathrm{sec}$ rest). The soluble chromatin fraction was quantitated and $100 \mathrm{mg}$ of chromatin was precleared with $10 \mu \mathrm{l}$ of Protein A Dynabeads (Invitrogen) for $2 \mathrm{~h}$, then incubated overnight at $4^{\circ} \mathrm{C}$ with $1.5 \mu \mathrm{g}$ of either YB-1 (9744S; Cell Signaling), or rabbit IgG (PI31887; Thermo Scientific) antibodies. The following day, $10 \mu \mathrm{l}$ of Dynabeads were added to the chromatin-antibody mixture and incubated with rotation for $2 \mathrm{~h}$ at $4^{\circ} \mathrm{C}$. ChIPs were washed with a low salt wash buffer (20-154; Millipore), high salt wash buffer (20-155; Millipore), and TE (20-157; Millipore). Crosslinks were reversed overnight at $65^{\circ} \mathrm{C}$, followed by RNAse (Qiagen) at $37^{\circ} \mathrm{C}$ for $2 \mathrm{~h}$, and proteinase $\mathrm{K}$ (Qiagen) at $55^{\circ} \mathrm{C}$ for $2 \mathrm{~h}$. DNA was eluted using Qiaquick PCR purification kit (Qiagen) and amplified by reverse transcription-quantitative PCR (RT-qPCR). Data was analyzed using the \% input method. Firstly, input $\mathrm{Cq}$ was adjusted to $100 \%$ (Cq input-4.24). Results from immunoprecipitated samples were analyzed using the following calculation: $100 \times 2^{\wedge}$ [adjusted input-Cq (IP)]. Fold difference was calculated against the negative control (rabbit $\mathrm{IgG}$ ).

$R T$ - $q P C R$ and mRNA stability assay. 24-h post transfection with siRNAs as described above, cells were re-plated into duplicate $60 \mathrm{~mm}$ plates for actinomycin time-course treatment. At $48 \mathrm{~h}$ post transfection, actinomycin treatment was initiated with $10 \mu \mathrm{g} / \mathrm{ml}$ of actinomycin D added to appropriate dishes. Treated samples were harvested at $0,3,6$, and $9 \mathrm{~h}$ after 
Table I. Primers for qPCR and ChIP.

\begin{tabular}{ll} 
Primers & \multicolumn{1}{c}{ Sequence (5'-3') } \\
\hline $\begin{array}{l}\text { qPCR primers } \\
\beta \text {-actin forward }\end{array}$ & \\
$\beta$-actin reverse & ATC CAC GAA ACT ACC TTC AAC TC \\
YB-1 forward & GAG GAG CAA TGA TCT TGA TCT TC \\
YB-1 reverse & AAG TGA TGG AGG GTG CTG ACA ACC A \\
SCD1 forward & GGC GTC TGC GTC GGT AAT TGA AGT T \\
SCD1 reverse & GTT CCA GAG GAG GTA CTA CAA ACC TGG \\
EGFR forward & GTA GTT GTG GAA GCC CTC ACC CA \\
EGFR reverse & GCG TTC GGC ACG GTG TAT AAG GGA CTC \\
ChIP primers & GAG GCA GCC GAA GGG CAT GAG C \\
SCD1-1.5 kB Forward & \\
SCD1-1.5 kB Reverse & \\
SCD1-0.7 kB Forward & \\
SCD1-0.7 kB Reverse & AGA TCA GTA GGG TCA GAG CAT CTC AG \\
SCD1-0.2 kB Forward & CTG CAA GCC AAT TCA CAA GAA TCG TT \\
SCD1-0.2 kB Reverse & GAG GGT TCA CCA CTG TTT CCT GAG \\
\hline
\end{tabular}

qPCR, quantitative polymerase chain reaction; ChIP, chromatin immunoprecipitation; YB-1, Y-box binding protein 1; SCD1, stearoyl-CoA desaturase; EGFR, epidermal growth factor receptor.

actinomycin treatment. Total RNA was obtained from cells by Qiazol extraction and RNeasy purification (Qiagen). YB-1 and SCD1 mRNA levels were determined using RT-qPCR using a Rotor-gene Q PCR machine. Primer sequences are presented in Table I. The data were analyzed using the $2^{-\Delta \Delta \mathrm{Cq}}$ method and the Actin mRNA was used as an endogenous control as previously described (42). SCD1 mRNA levels were plotted against time after actinomycin $\mathrm{D}$ addition and fitted to a linear regression model. SCD1 mRNA half-life was calculated using the linear regression model. Data were analyzed with the unpaired Student's t-test with Bonferroni correction and are presented as the mean \pm standard deviation. Experiment was carried out in triplicate.

Statistical analysis. All experiments were performed in triplicate $(n=3)$. An unpaired two-tailed Student's t-test with two degrees of freedom was used to compare means of the three replicate experiments between treatments using either GraphPad Prism or MS Excel. Where appropriate, the Bonferroni correction was applied to t-tests. $\mathrm{P}<0.05$ was considered to indicate a statistically significant difference.

Bioinformatic analysis. CcRCC Reverse Phase Protein Array (RPPA) data $(\mathrm{n}=445)$ was obtained from KIRC (Clear cell Renal carcinoma) dataset from The Cancer Proteome Atlas (TCPA) maintained by The University of Texas MD Anderson Cancer Center, available at http://tcpaportal.org/tcpa. The Kaplan-Meier analysis of overall survival (OS) was done using the 'survfit' function from Bioconductor package (https://rdrr.io/cran/survival/src/R/survfit.R) in R statistical software package (v3.4.2). Association between OS and key proteins was determined by univariable Cox proportional Hazard models. Associations between key proteins of interest were determined by multivariate pairwise analysis using Spearman ranked correlations for each pair of set of variables $(\mathrm{P}<0.05$ implies a statistically significant marginal association at the 0.05 alpha level). Multivariate analysis was done using proportion of pairwise correlations in JMP software by SAS.

\section{Results}

MUFA increases protein synthesis in ccRCC. The production of MUFA is essential for basic cellular function in mammalian cells. In the production of membranes, the principal fatty acids utilized are unsaturated, oleic acids and palmitoleic acids. Previous work has demonstrated that oleic acid stabilizes the proto-oncogene $\beta$-catenin in kidney cancer cells (10). To identify other potential fatty-acid stabilized proteins, we performed proteomic analysis on cells following lipid depletion and replenishment with unsaturated fatty acids. Proteins were grouped into categories based on biological processes using PantherDB Gene Ontology Software. Several of the enrichment groupings were related to protein biosynthetic mechanisms (Fig. 1A). To confirm these data, we conducted protein synthesis analysis using either incorporation of radiolabeled-methionine or incorporation of puromycin-analogs into growing peptide chains in kidney cancer cells. In radiolabeling experiments we used ccRCC cell line, SW156, and non-tumorigenic human fibroblasts as controls. Results showed that the presence of MUFAs led to increased protein synthesis only in ccRCC cells (Fig. 1B). Next, we briefly treated an additional ccRCC cell line, 786-O, with both saturated and unsaturated fatty acids, and measured subsequent protein production. In the presence of oleic acid, protein synthesis was increased while in the presence of other fatty acids, such as saturated palmitic acid, protein production was unchanged or inhibited 
A

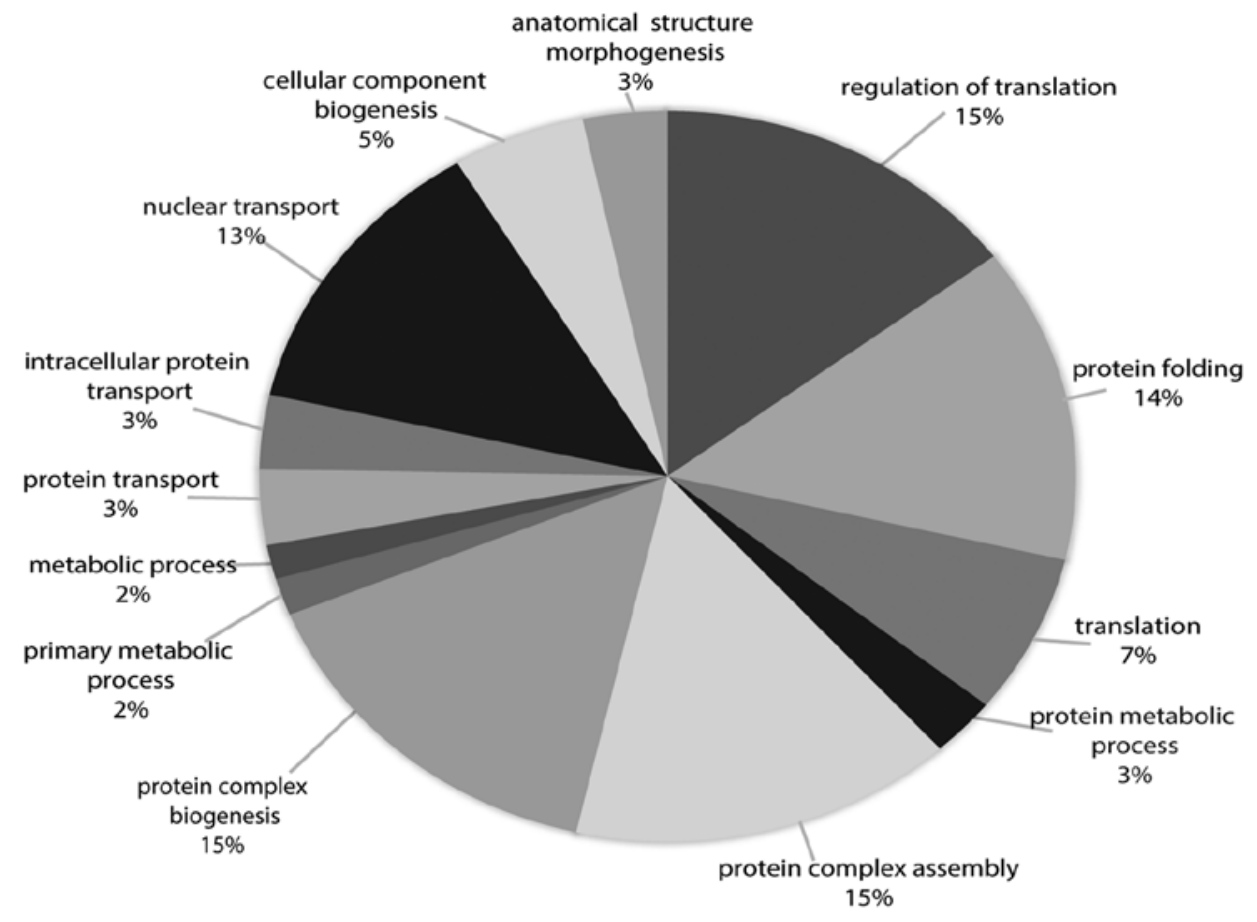

B

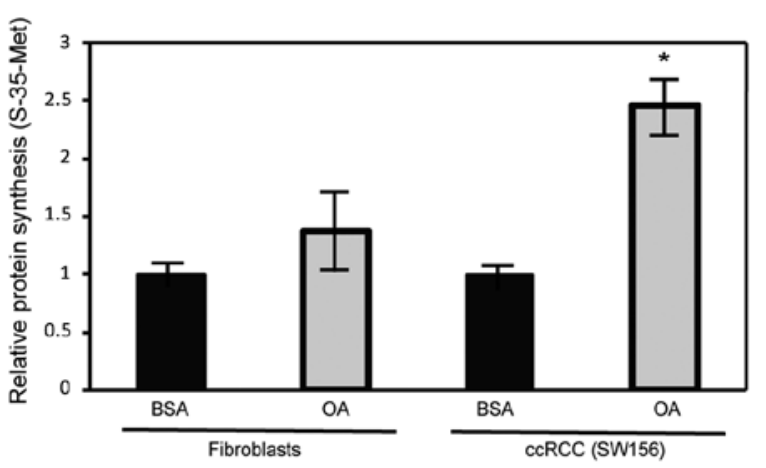

C

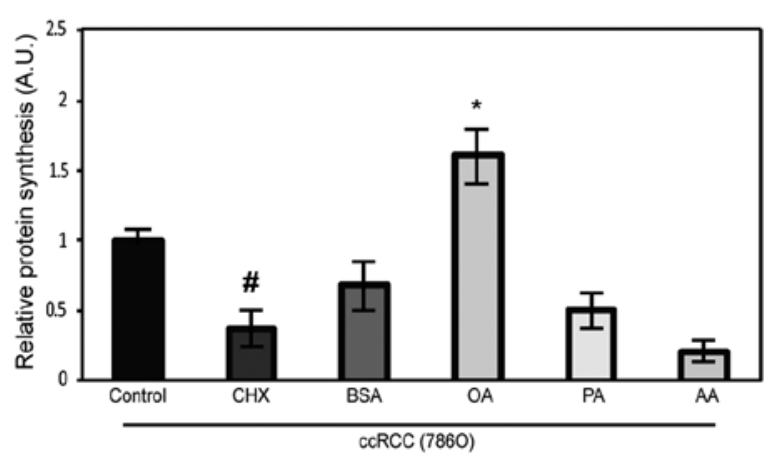

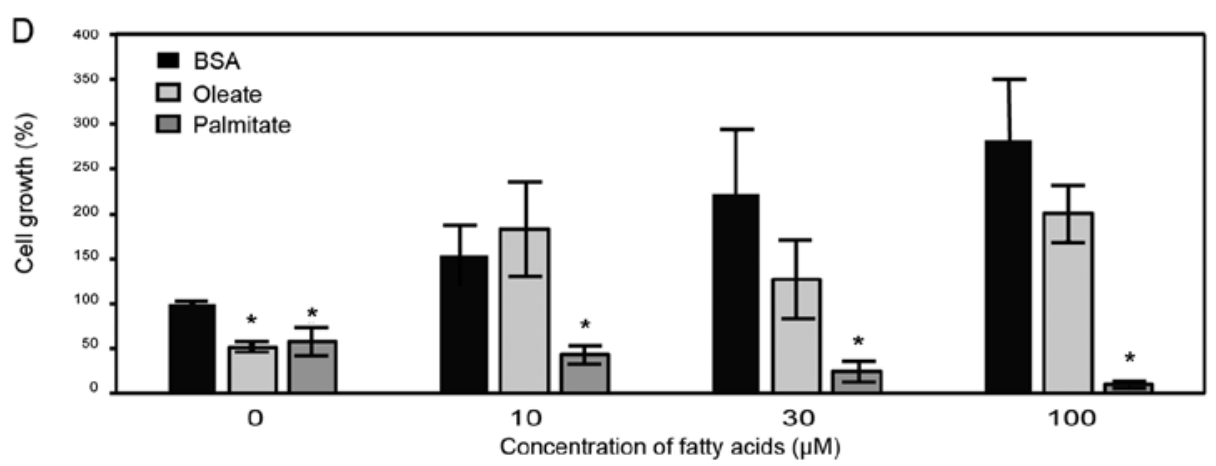

Figure 1. MUFA increases global protein synthesis in ccRCC cells. (A) Summarized Stable Isotope labeling of Amino Acids in Cell Culture study data showing biological processes associated with proteins enriched in lipid deprived cells exposed to 4-h incubation with MUFA. (B) Protein synthesis in non-tumorigenic SV589 fibroblast and tumorigenic SW156 ccRCC cells treated by lipid depletion and 4-h MUFA exposure was measured by methionine incorporation. (C) Protein synthesis in tumorigenic 786-O ccRCC cells treated 4-h with $100 \mu \mathrm{M}$ FA or BSA, following overnight lipid depletion. (D) Cell growth was measured in 786-O ccRCC cells following lipid depletion/MUFA exposure by Cell Titer-Glo cell as described in Methods. Results are reported as mean \pm standard deviation from triplicate experiments $(\mathrm{n}=3)$. " $\mathrm{P}<0.05$ vs. BSA; " $\mathrm{P}<0.05$ vs. Control. OA, oleate; PA, palmitate; AA, arachidonate; ccRCC, clear cell renal cell carcinoma; MUFA, monounsaturated fatty acids; FA, fatty acids.

(Fig. 1C). To determine other relevant biological effects of MUFA in our model of ccRCC, we performed proliferation assays on oleate-exposed cells following overnight lipid deprivation with media containing SCD1 inhibitors. The results indicate that lipid replenishment with different concentrations of oleate, led to a remarkable increase in cell growth, which is likely related to increased protein synthesis observed in previous experiments (Fig. 1D). 
A

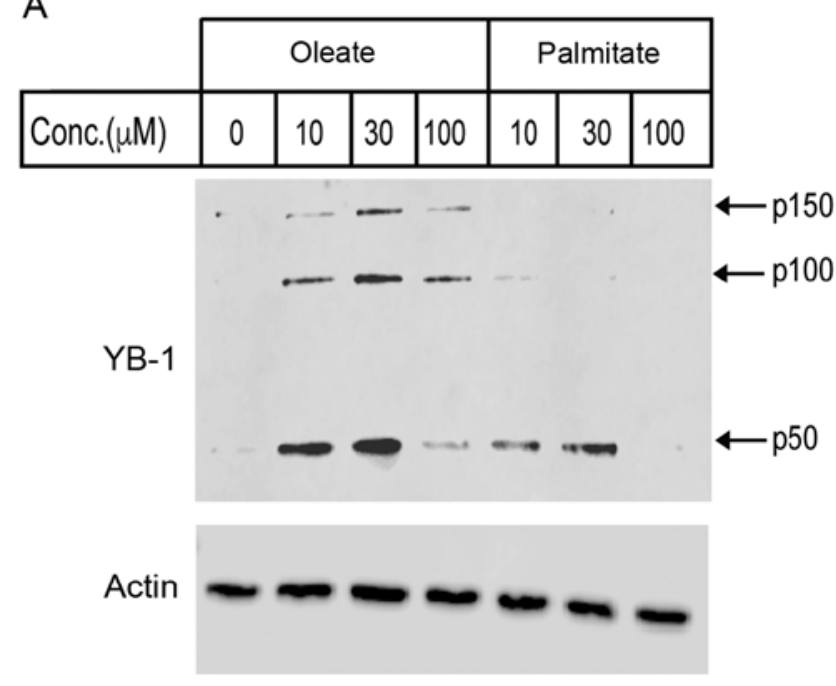

B

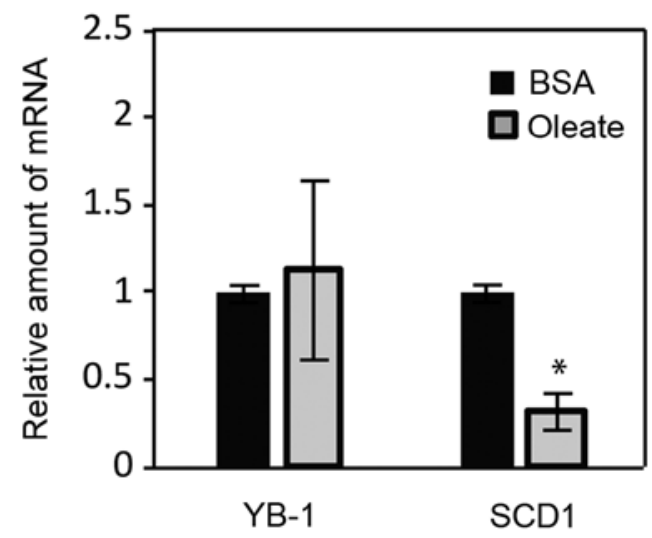

Figure 2. MUFA increases intracellular levels of YB-1 protein, but not mRNA. (A) Immunoblot analysis of YB-1 expression in cells treated by lipid depletion and increasing concentrations of MUFA, oleate or saturated fatty acid, palmitate. (B) Expression of YB-1 and SCD1 mRNA in cells treated by lipid depletion and exposure to $30 \mu \mathrm{M}$ oleate was measured by reverse transcription-quantitative PCR. Results of immunoblot is a representative of more two experiments. Results are reported as mean \pm standard deviation from triplicate experiments $(n=3)$. ${ }^{*} \mathrm{P}<0.05$ vs. BSA. YB-1, Y-box binding protein 1 .

MUFA increases $Y B-1$ protein expression in ccRCC. Data from the proteomics analysis indicated an enrichment of proteins involved in protein synthesis. Therefore, we searched through the proteins in our dataset to identify proteins that could potentially regulate translation and/or protein synthesis. The top protein candidate was YB-1, which could promote and suppress translation of target transcripts. To confirm that YB-1 was sensitive to the cellular levels of unsaturated fatty acid, we measured intracellular levels of YB-1 in lipid-deprived ccRCC cells following brief exposure to varying concentrations of saturated and unsaturated fatty acids. The presence of fatty acids increased the level of $50 \mathrm{kDa}$ monomeric, YB-1 (p50) (Fig. 2A). However, the notable decrease of YB-1 in cells treated with $100 \mu \mathrm{M}$ oleate was likely related to YB-1 packing into exosomes as described by others (43), while decrease of YB-1 in palmitate-treated cells was likely due to lipotoxicity (44). Interestingly, we observed a significant enrichment in high molecular weight forms of YB-1 (p100 and p150) with oleate-treated, but not palmitate-treated samples (Fig. 2A). This high molecular weight YB-1, which had been previously demonstrated to be the result of transglutaminase activity in activated fibroblasts, has decreased RNA-binding capacity compared to the YB-1 p50 monomer (34). As done in studies by Willis et al, we confirmed that endogenous transglutaminase activity in ccRCC cells was involved, to some extent, in YB-1 oligomerization by treating cultured cells with transglutaminase inhibitor, cystamine prior to immunoblot analysis (data not shown) (34). To determine whether the changes in abundance of YB-1 protein was due to increased transcription, we performed real-time quantitative PCR (qPCR) on oleate-treated ccRCC cells. We analyzed SCD1 mRNA as well, to determine if there was any negative feedback on oleic acid production during our treatment. When cells were treated with oleate-BSA, $Y B 1$ mRNA did not change, which suggested that $Y B 1$ was not a lipid-responsive gene (Fig. 2B, left). However, there was a significant decrease in SCDI mRNA in the presence of oleate-BSA which confirmed the presence of intact negative feedback regulation in the lipogenic pathway as expected (Fig. 2B).

Overexpression of $Y B-1$ decreases expression of SCD1 in $c c R C C$. While the level of MUFA appeared to affect YB-1 protein expression and oligomerization, the consequence remained unclear. We sought to determine if there was a relationship between YB-1 and SCD1. Thus, we overexpressed YB-1 in ccRCC cells using plasmid DNA, and then measured the effects on SCDI mRNA and protein. Following transfection with YB-1, there was a decrease in SCD1 protein, as determined by immunoblot analysis (Fig. 3A). We confirmed the results of the protein analysis using $\mathrm{qPCR}$, which had also shown a significant decrease in SCD1 mRNA in YB-1-transfected cells compared to controls (Fig. 3B and C). Taken together, the data illustrate that YB-1 is involved in suppressing the expression of SCD1 mRNA, however it did not indicate whether this was due to a direct or indirect effect on transcription or stability of SCDI mRNA.

Knockdown of YB-1 increases expression of SCDI in $c c R C C$. Analysis of mRNA following transfection showed that increased YB-1 expression inhibits expression of SCD1 mRNA in ccRCC. To determine whether this was dependent on inhibition of transcription or decreased mRNA stability, we first looked to decrease cellular levels of YB-1 using RNA interference. Cells were transfected with anti-sense $Y B 1$ oligos for $48 \mathrm{~h}$ and then total mRNA was isolated for qPCR analysis. A substantial level of knockdown was confirmed by qPCR (Fig. 4A, right panel). We also observed a corresponding increase in SCD1 mRNA, that agreed with our previous observations (Fig. 4A, left panel). To measure the effect of YB-1 on the stability of $S C D 1$ mRNA, we looked at RNA decay rates in cells with $Y B 1$ knocked-down. First, total mRNA was assessed over a 9-h time course following treatment with the transcription inhibitor, Actinomycin D. Transcripts for $Y B 1$ remained significantly diminished compared to control at 
A

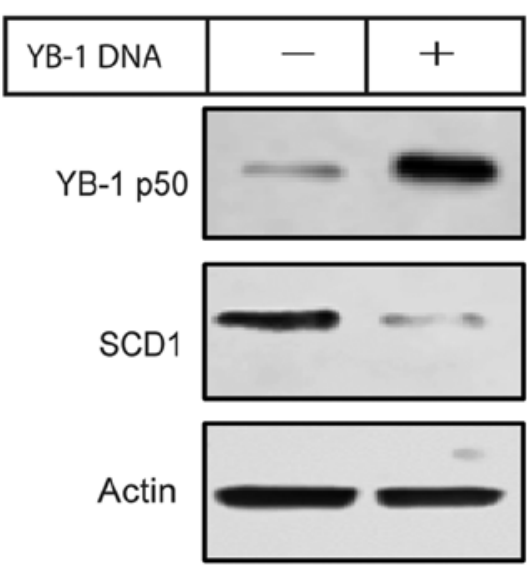

B

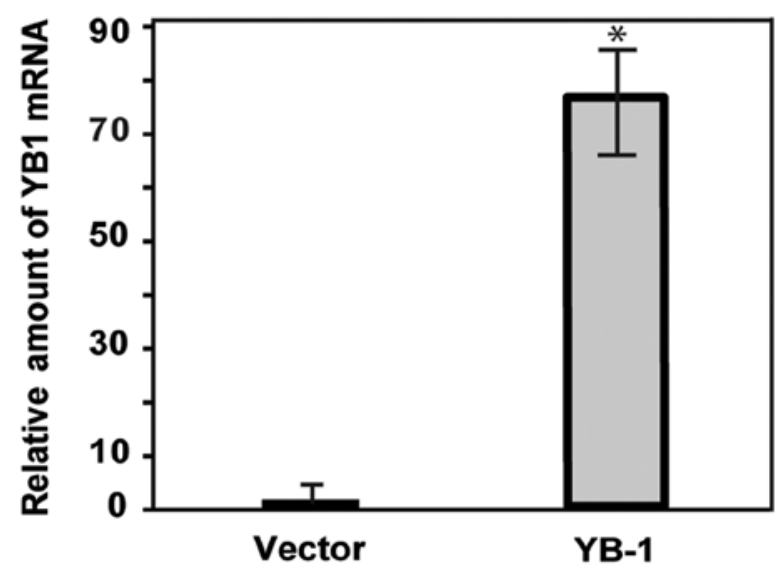

C

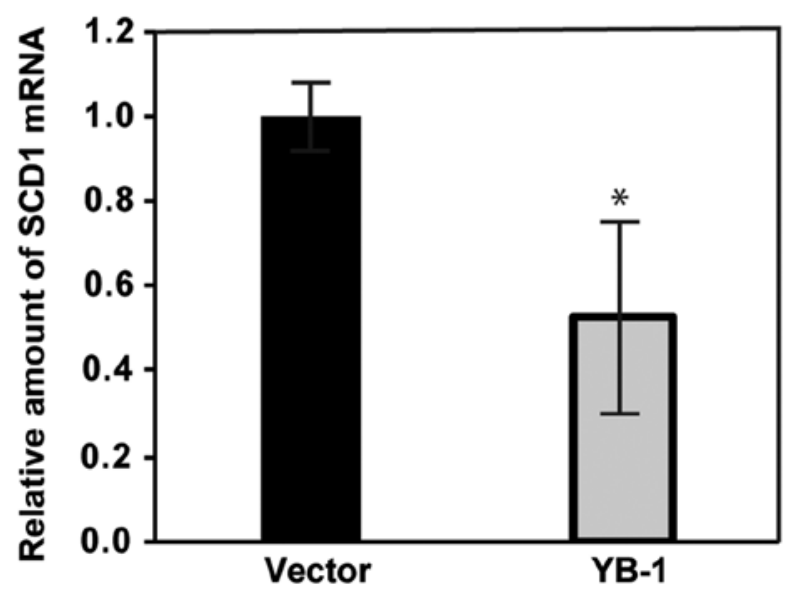

Figure 3. Overexpression of YB-1 inhibits expression of SCD1 protein (A) The level of YB-1 and SCD1 protein expressed was detected by immunoblot analysis 24-h post-transfection. (B and C) Relative level of mRNA for YB-1 and SCD1 following YB-1 transfection was determined by reverse transcription-quantitative PCR analysis. Results are reported as mean \pm standard deviation from triplicate experiments, $n=3$. ${ }^{*} \mathrm{P}<0.05$ vs. Vector. YB-1, Y-box binding protein 1; SCD1, stearoyl-CoA desaturase.

each time point (Fig. 4B). Levels of SCD1 mRNA increased with $Y B 1$ knockdown, while the assay control gene, epidermal growth factor receptor $(E G F R)$ showed an increase in mRNA compared to control at each time point (Fig. 4B). To determine the effects of YB-1 on transcript stability, we analyzed the mRNA levels at each timepoint relative to $\mathrm{t}=0$. Transcripts for SCD1 did not appear to change over time, while EGFR,
Table II. Summary of univariable associations with overall survival in patients with ccRCC.

\begin{tabular}{lcccl}
\hline Marker & $\begin{array}{c}\text { Hazard } \\
\text { ratio }\end{array}$ & $\begin{array}{c}\text { Lower } \\
0.95 \mathrm{CI}\end{array}$ & $\begin{array}{c}\text { Upper } \\
0.95 \mathrm{CI}\end{array}$ & P-value \\
\hline YB-1 & 1.96 & 1.33 & 2.88 & 0.0006 \\
YB-1 pS102 & 1.77 & 1.36 & 2.3 & 0.00002 \\
SCD1 & 0.23 & 0.09 & 0.55 & 0.0009 \\
\hline
\end{tabular}

ccRCC, clear cell renal cell carcinoma; YB-1, Y-box binding protein 1; SCD1, stearoyl-CoA desaturase.

a normally high-turnover transcript, decreased over time as expected in control transfected cells (45) (Fig. 4C). This demonstrated that $S C D 1$ is a relatively stable transcript, even when YB-1 is decreased (Fig. 4C). This indicates that decreasing YB-1 does not affect SCD1 translation, but does lead to increased transcription of SCD1 mRNA, which can lead to the increased production of MUFA in cancer cells.

To further demonstrate that YB-1 influenced the transcription of $S C D 1$, we decided to show the effect of MUFA on YB-1 binding to the $S C D 1$ promoter. To identify potential binding sites and aid in the design of chromatin immunoprecipitation (ChIP) primers for the SCDI gene promoter, we utilized the 8th release of JASPAR, the open access transcription factor binding profile database (46). We designed three sets of primers that covered roughly 2 kilobases $(2 \mathrm{kB})$ of the upstream region of $S C D 1$, with one set of primers flanking the JASPAR predicted YB-1 binding site (Fig. 5A). 786-O cells were deprived of lipids and replenished with oleate-BSA or BSA alone as previously described, before being prepared for chromatin immunoprecipitation quantitative PCR (ChIP-qPCR) analysis as described in the methods section. Following immunoprecipitation, YB-1 was highly enriched at the predicted binding site compared to IgG control, with lower levels of signal observed along the SCD1 gene promoter. When cells were replenished with $100 \mu \mathrm{M}$ oleate-BSA, YB-1-associated DNA is noticeably decreased (Fig. 5B). These data all together suggest that YB-1 binding to $S C D 1$ promoter is sensitive to the level of MUFA in the cell and indicates a potential feedback mechanism between YB-1 and fatty acid levels in ccRCC.

$Y B-1$ protein is negatively correlated with survival, but SCD1 improves survival. Given that YB-1 and SCD1 have documented roles in cancer, we next sought to explore the consequences of differential expression of each protein in ccRCC patients. To accomplish this, we downloaded ccRCC (KIRC) patient datasets from The Cancer Genome Atlas (47). We then sorted patients based on the availability of protein expression (reverse-phase protein arrays, RPPA) and clinical data. We determined the association between patient overall survival (OS) and each protein of interest using univariable Cox proportional Hazard models. The results of the analysis showed a strong association between each of the proteins and OS (P-value <0.05) (Table II). YB-1, and its phosphorylated form (pS102-YB-1), were both negatively associated with OS (i.e. high expression is associated with decreased survival 
A

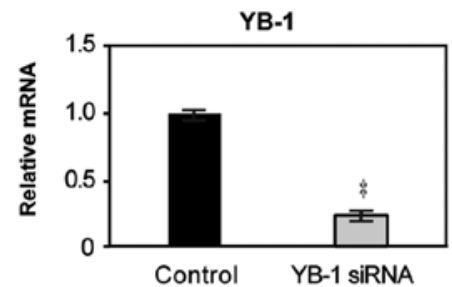

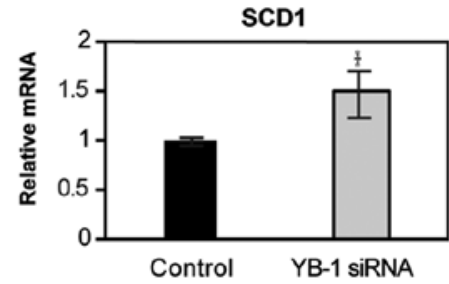

SCD1
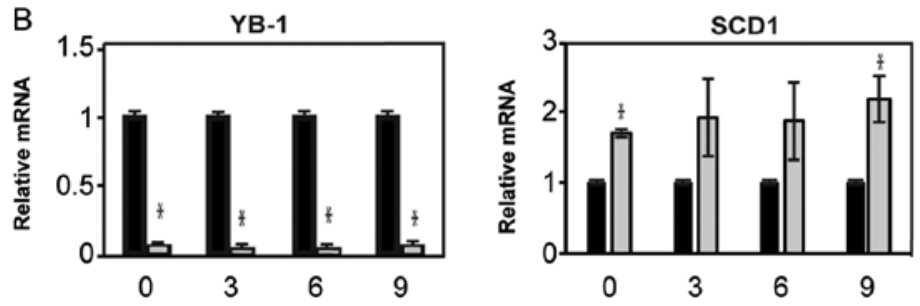

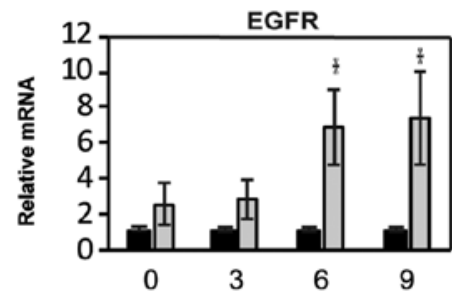

Actinomycin $\mathrm{D}$ treatment $(\mathrm{h})$

- Control siRNA

YB-1 siRNA

C

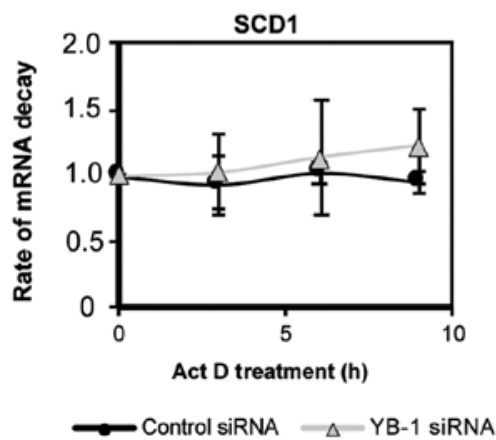

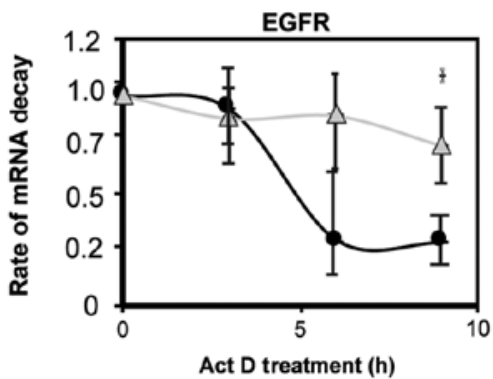

$\longrightarrow$ Control siRNA $\triangle-$ YB-1 siRNA

Figure 4. Knockdown of YB-1 increases the level of SCD1 mRNA. (A) Relative level YB-1 and SCD1 mRNA following transfection with YB-1 siRNA was measured by RT-quantitative PCR. (B) Relative abundance of $Y B-1, S C D 1$ and EGFR mRNA at each time point during actinomycin D treatment as measured by RT-qPCR. (C) Relative rate of mRNA decay was measured by comparing relative levels of $S C D 1$ and EGFR mRNA at each time point to mRNA amount at $\mathrm{t}=0$. Results are reported as mean \pm standard deviation from triplicate experiments, $\mathrm{n}=3$. " $\mathrm{P}<0.05$ vs. Control siRNA. YB-1, Y-box binding protein 1 ; SCD1, stearoyl-CoA desaturase; RT-qPCR, reverse transcription-quantitative PCR; siRNA, small interfering RNA.

A

Predicted YB-1 binding site

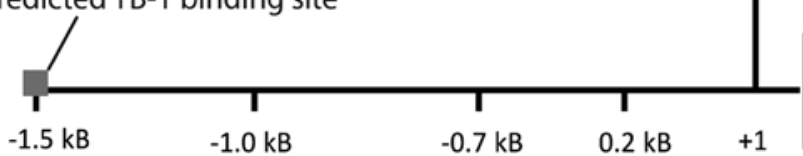

\section{SCD1}

B

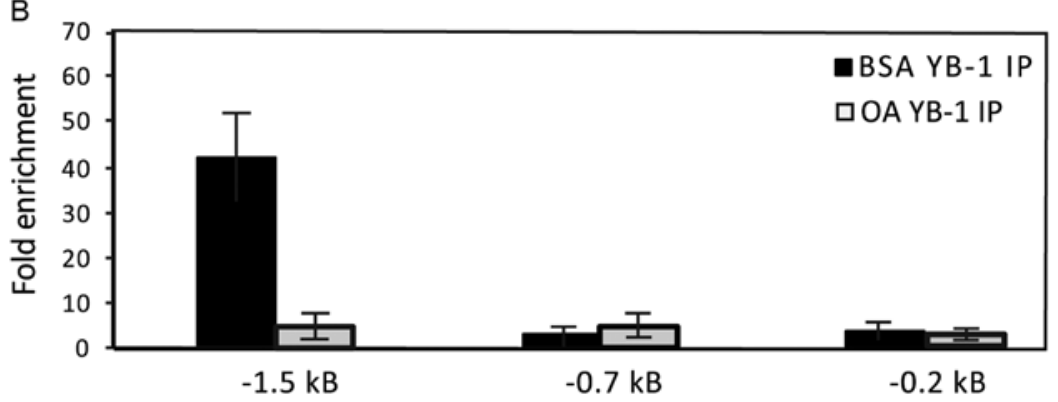

SCD1 promoter regions

Figure 5. MUFA decreases the binding of YB-1 to the SCD1 promoter. (A) The sequence of the 5'-untranslated region of SCD1 was aligned with the predicted YB-1 binding sequence obtained from JASPAR 2020 online database. (B) Binding of YB-1 to the promoter was determined by chromatin immunoprecipitation-quantitative PCR using primers to multiple regions of the $S C D 1$ promoter (described in A). The data presented is the mean of two experiments and error bars represent the standard deviation of the sample means. YB-1, Y-box binding protein 1; SCD1, stearoyl-CoA desaturase; OA, oleate. 
A

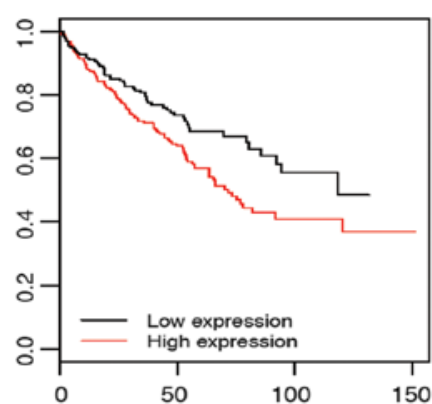

D

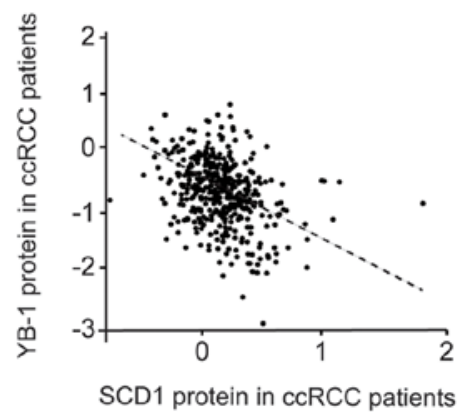

B

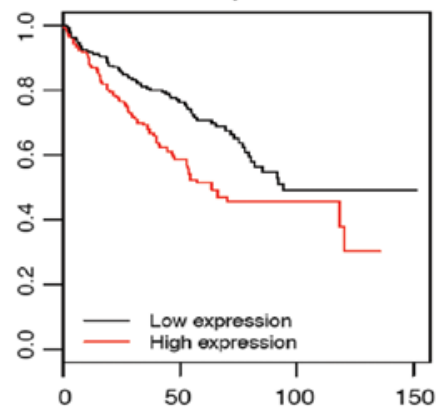

C

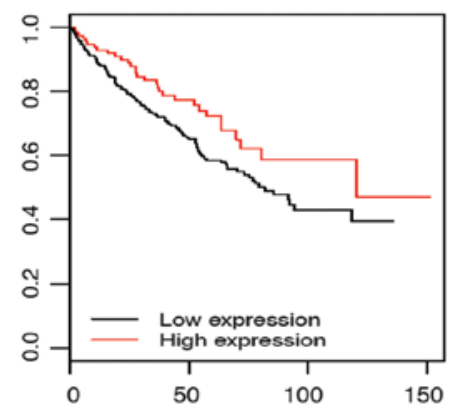

E

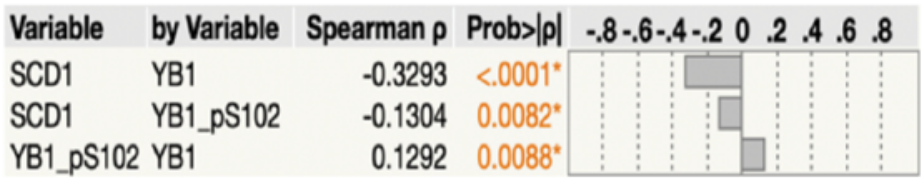

Figure 6. YB-1 expression is negatively correlated to SCD1 protein in ccRCC patients in TCGA KIRC dataset. (A-C) YB-1, YB-1 phosphoserine 102, and SCD1 protein expression levels were compared to survival in Kaplan-Meir plots generated using patient data from the TCGA RPPA dataset. (D) Comparison between YB-1 and SCD1 protein expression in ccRCC patients in KIRC dataset using Scatterplot analysis. (E) Results of Spearman rank correlation analysis between set pairs of proteins. Statistical analysis of data is detailed in Methods. YB-1, Y-box binding protein 1; SCD1, stearoyl-CoA desaturase; ccRCC, clear cell renal cell carcinoma; TCGA, The Cancer Genome Atlas.

$\underline{\text { YB-1-mediated repression of scd } 1}$
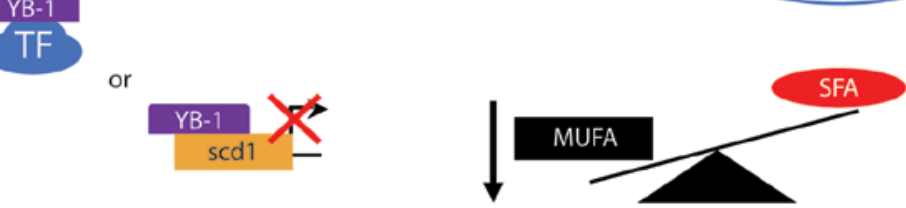

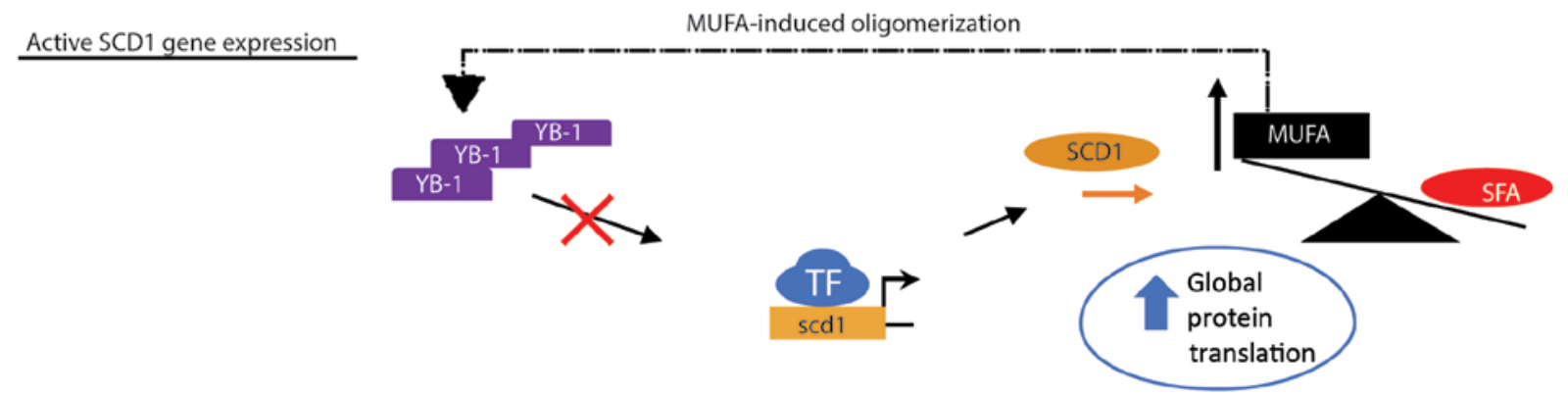

MUFA-induced oligomerization

Figure 7. Model of the regulation SCD1 by YB-1 in ccRCC cells. Increased YB-1 in the cell leads to decreased transcription of SCD1, either by inhibiting the activity of a necessary and yet unknown transcription factor, or by binding directly to the SCD1 promoter to suppress transcription. Increased in SCD1 protein in cells leads to increased MUFA and accumulation of oligomerized YB-1. MUFA, monounsaturated fatty acids; SFA, saturated fatty acids; YB1, Y-box binding protein 1; TF, transcription factor; SCD1, stearoyl-CoA desaturase.

time), the hazard ratio for YB-1 was 1.96 (95\% CI: 1.33 , $2.88)$ and the hazard ratio for pS102-YB-1 was 1.77 (95\% CI: 1.36, 2.3). Conversely, high expression of SCD1 was strongly associated with improved OS, hazard ratio of 0.23 (95\% CI:
$0.09,0.55)$. Kaplan Meir plots were generated to graphically depict these results (Fig. 6A-C). We next explored the relationship between SCD1 and YB-1, by analyzing the strength of the correlation between the expression of each protein in the 
patient data. The correlation that was observed was consistent with our molecular studies, and showed a strong negative correlation between SCD1 and YB-1 (Fig. 6D and E). Thus, the expression of YB-1 protein in patients has a negative impact on SCD1 expression which may contribute to decreased patient survival. To explain how this may work physiologically, we developed a graphical model (Fig. 7). In the model, we predict that SCD1 expression is negatively affected by YB-1. In our model, increases in YB-1 protein leads to a decrease in SCDI mRNA synthesis and subsequently decreases cellular levels of MUFA. Conversely in our model, increased SCD1 results in increased cellular MUFA which functions to increase YB-1 oligomerization. Oligomerization of YB-1 presumably dampens the inhibitory effect of YB-1 on SCD1, through an undefined mechanism, resulting in increased levels of SCDI mRNA transcripts.

\section{Discussion}

In the present study, we present data indicating that $\mathrm{YB}-1$ is a negative regulator of SCD1 in clear cell Renal Carcinoma (ccRCC). CcRCC is often laden with additional fat stored in the cytosol. Historically, the presence of increased fatty acids was thought to contribute to patient resistance to treatment (48). We began our work by investigating how increased fatty acids supported differential protein expression in cancer cells. We were able to demonstrate that the presence of monounsaturated fatty acid is associated with increased overall level of protein synthesis in different ccRCC cell lines compared to non-tumorigenic cells. This mechanism of increased protein expression was categorically different from that demonstrated in previous studies, where protein degradation was inhibited by the presence of MUFA (10).

Further, we showed that YB-1, an oncogene that is associated with aggressive tumor growth and poor overall survival in patients, was sensitive to the presence of monounsaturated fat. Because we saw little shift in the levels of $Y B 1$ mRNA in the presence of MUFA, we suspected that YB-1 protein synthesis was increased under lipid depletion/replenishment conditions.

Interestingly, we were able to show that YB-1 expression caused a decrease in the expression of SCD1, independent of MUFA treatment. Furthermore, we confirmed the directionality of this relationship by illustrating that $Y B 1$ knockdown resulted in increased levels of SCDI mRNA. It was determined that SCDI mRNA was stable even in the absence of YB-1, which ruled out alterations in mRNA stability or direct changes in translation. In absence of YB-1, EGFR mRNA also showed some interesting trends in our study, however it was only included as a known control for mRNA turnover, the relationship between YB-1 and EGFR will be investigated in future studies. Prompted by the effects of YB-1 knockdown on SCD1 mRNA levels, we sought to analyze interactions between YB-1 and SCDI DNA. Chromatin immunoprecipitation data suggest that the $S C D 1$ transcription is likely inhibited by YB-1 protein occupying a region $1.5 \mathrm{kB}$ upstream of the SCD1 transcription start site, in the absence of MUFA. This indicates that YB-1 behaves as a negative regulator of SCDI transcription when fatty acids levels are below a certain threshold.
Finally, as YB-1 has been demonstrated to drive cancer growth in patients, we became interested in identifying correlations in expression between YB-1 and SCD1 protein in renal cancer patients. Our bioinformatic analysis of several hundred patients' records, confirmed our in vitro findings to show that YB-1 is negatively associated with SCD1 at the protein level. However, the most interesting finding was that SCD1 had a largely positive association with patient survival. Meaning that in our patient population, individuals whose tumors had increased levels of SCD1 protein had a statistically significant increase in 5-year survival compared to patients with less tumor associated SCD1 protein. While this may conflict with previous cancer studies looking at SCDI mRNA levels and limited immunohistochemical assessments, this agrees with previous studies in yeast, nematodes, and human cells that demonstrated a general benefit to cellular health and longevity in the presence of MUFAs, such as oleate $(8,23,25,49,50)$. To the best of our knowledge, this is the first report that implicates YB-1 as a regulator of lipogenic genes. Furthermore, this is one of the first reports to suggest that SCD1 expression may antagonize the development of more aggressive cancer phenotypes in patients. A similar study of SCD1 in CML also questions the only role of SCD1 as an oncogene, and demonstrates its potential as a tumor suppressor (51). Based on our findings, it appears that investigating the potential benefit of measuring YB-1 and SCD1 gene expression in patients should be considered, while implementation of any SCD1-targeted therapies should be done with considerable precaution.

\section{Acknowledgements}

The authors would like to acknowledge the support of Ms. Jara McLaren (Simmons Laboratory, UMN Medical School) for providing an early review of the literature regarding function and localization of YB-1 in the context of cancer; Mrs. Barbara Perslin (Department of Biomedical Sciences, UMN Medical School) for administrative support in the ordering of supplies and reagents; Dr Benjamin Clarke (UMN Medical School) for providing the tissue culture facilities for the work done for this manuscript; Mrs. Shannon RedBrook (Clarke Lab) for technical support regarding use of the Clarke laboratory tissue culture facility; and Dr Jean Regal (Department of Biomedical Sciences, UMN Medical School) for orchestrating critical staff support to the project.

\section{Funding}

This work was supported by the Whiteside Institute for Clinical Research and by the National Institutes of Health's National Center for Advancing Translational Sciences (grant no. UL1TR002494). The content is solely the responsibility of the authors and does not necessarily represent the official views of the National Institutes of Health's National Center for Advancing Translational Sciences.

\section{Availability of data and materials}

The datasets used and/or analyzed during the present study are available from the corresponding author on reasonable request. 


\section{Authors' contributions}

EJ, SF, BC, KR, TC, RM, LB and GES designed studies and analyzed data. EJ and GES wrote the manuscript. EJ, SF, BC, KR, TC, RGM, LB and GES performed experiments. GES supervised the entire study. All authors have read and approved the final manuscript.

\section{Ethics approval and consent to participate}

Not applicable.

\section{Patient consent for publication}

Not applicable.

\section{Competing interests}

The authors declare that they have no competing interests.

\section{References}

1. Noone AM, Cronin KA, Altekruse SF, Howlader N, Lewis DR, Petkov VI and Penberthy L: Cancer incidence and survival trends by subtype using data from the surveillance epidemiology and end results program, 1992-2013. Cancer Epidemiol Biomarkers Prev 26: 632-641, 2017.

2. Wang H, Zhang Y, Lu Y, Song J, Huang M, Zhang J and Huang Y The role of stearoyl-coenzyme A desaturase 1 in clear cell renal cell carcinoma. Tumour Biol 37: 479-489, 2016.

3. Zaidi N, Lupien L, Kuemmerle NB, Kinlaw WB, Swinnen JV and Smans K: Lipogenesis and lipolysis: The pathways exploited by the cancer cells to acquire fatty acids. Prog Lipid Res 52: 585-589, 2013

4. Ameer F, Scandiuzzi L, Hasnain S, Kalbacher H and Zaidi N: De novo lipogenesis in health and disease. Metabolism 63: 895-902, 2014.

5. Vriens K, Christen S, Parik S, Broekaert D, Yoshinaga K, Talebi A, Dehairs J, Escalona-Noguero C, Schmieder R, Cornfield T, et al: Evidence for an alternative fatty acid desaturation pathway increasing cancer plasticity. Nature 566: 403-406, 2019.

6. Iwamoto H, Abe M, Yang Y, Cui D, Seki T, Nakamura M, Hosaka K, Lim S, Wu J, He X, et al: Cancer lipid metabolism confers antiangiogenic drug resistance. Cell Metab 28: 104-117, 2018.

7. Ntambi JM: Regulation of stearoyl-CoA desaturase by polyunsaturated fatty acids and cholesterol. J Lipid Res 40: 1549-1558, 1999.

8. Falvella FS, Pascale RM, Gariboldi M, Manenti G, De Miglio MR Simile MM, Dragani TA and Feo F: Stearoyl-CoA desaturase 1 (Scd1) gene overexpression is associated with genetic predisposition to hepatocarcinogenesis in mice and rats. Carcinogenesis 23 : 1933-1936, 2002.

9. von Roemeling CA, Marlow LA, Pinkerton AB, Crist A, Miller J, Tun HW, Smallridge RC and Copland JA: Aberrant lipid metabolism in anaplastic thyroid carcinoma reveals stearoyl CoA desaturase 1 as a novel therapeutic target. J Clin Endocrinol Metab 100: E697-E709, 2015.

10. Kim H, Rodriguez-Navas C, Kollipara RK, Kapur P, Pedrosa I, Brugarolas J, Kittler R and Ye J: Unsaturated fatty acids stimulate tumor growth through stabilization of beta-catenin. Cell Rep 13 $495-503,2015$.

11. Soto-Guzman A, Navarro-Tito N, Castro-Sanchez L, Martinez-Orozco R and Salazar EP: Oleic acid promotes MMP-9 secretion and invasion in breast cancer cells. Clin Exp Metastasis 27: 505-515, 2010.

12. von Roemeling CA and Copland JA: Targeting lipid metabolism for the treatment of anaplastic thyroid carcinoma. Expert Opin Ther Targets 20: 159-166, 2016.

13. Igal RA: Stearoyl-CoA desaturase-1: A novel key player in the mechanisms of cell proliferation, programmed cell death and transformation to cancer. Carcinogenesis 31: 1509-1515, 2010.
14. Roongta UV, Pabalan JG, Wang X, Ryseck RP, Fargnoli J, Henley BJ, Yang WP, Zhu J, Madireddi MT, Lawrence RM, et al: Cancer cell dependence on unsaturated fatty acids implicates stearoyl-CoA desaturase as a target for cancer therapy. Mol Cancer Res 9: 1551-1561, 2011.

15. Tosi MR, Fini G, Tinti A, Reggiani A and Tugnoli V: Molecular characterization of human healthy and neoplastic cerebral and renal tissues by in vitro (1)H NMR spectroscopy (review). Int J Mol Med 9: 299-310, 2002.

16. Tugnoli V, Reggiani A, Beghelli R, Tomaselli V, Trinchero A and Tosi MR: Magnetic resonance spectroscopy and high performance liquid chromatography of neoplastic human renal tissues. Anticancer Res 23: 1541-1548, 2003.

17. Tugnoli V, Bottura G, Fini G, Reggiani A, Tinti A, Trinchero A and Tosi MR: 1H-NMR and 13C-NMR lipid profiles of human renal tissues. Biopolymers 72: 86-95, 2003.

18. Mukherjee A, Kenny HA and Lengyel E: Unsaturated fatty acids maintain cancer cell stemness. Cell Stem Cell 20: 291-292, 2017.

19. Li J, Condello S, Thomes-Pepin J, Ma X, Xia Y, Hurley TD, Matei D and Cheng JX: Lipid desaturation is a metabolic marker and therapeutic target of ovarian cancer stem cells. Cell Stem Cell 20: 303-314.e5, 2017.

20. Kawahara I, Mori T, Goto K, Fujii K, Ohmori H, Kishi S, Fujiwara-Tani R and Kuniyasu H: Fatty acids induce stemness in the stromal cells of a CT26 mouse tumor model. Pathobiology 84 : 237-242, 2017.

21. Parrales A, Ranjan A and Iwakuma T: Unsaturated fatty acids regulate stemness of ovarian cancer cells through NF- $\kappa \mathrm{B}$. Stem Cell Investig 4: 49, 2017

22. Del Río LF, Gutiérrez-Casado E, Varela-López A and Villalba JM: Olive oil and the hallmarks of aging. Molecules 21: 163,2016

23. Imanikia S, Sheng M, Castro C, Griffin JL and Taylor RC: XBP-1 remodels lipid metabolism to extend longevity. Cell Rep 28: 581-589.e4, 2019

24. Giacosa A, Barale R, Bavaresco L, Faliva MA, Gerbi V, La Vecchia C, Negri E, Opizzi A, Perna S, Pezzotti M and Rondanelli M: Mediterranean way of drinking and longevity. Crit Rev Food Sci Nutr 56: 635-640, 2016.

25. Goudeau J, Bellemin S, Toselli-Mollereau E, Shamalnasab M, Chen Y and Aguilaniu H: Fatty acid desaturation links germ cell loss to longevity through NHR-80/HNF4 in C. elegans. PLoS Biol 9: e1000599, 2011.

26. Schaffer JE: Lipotoxicity: When tissues overeat. Curr Opin Lipidol 14: 281-287, 2003.

27. Schaffer JE: Lipotoxicity: Many roads to cell dysfunction and cell death: Introduction to a thematic review series. J Lipid Res 57: 1327-1328, 2016.

28. Noto A, Raffa S, De Vitis C, Roscilli G, Malpicci D, Coluccia P, Di Napoli A, Ricci A, Giovagnoli MR, Aurisicchio L, et al: Stearoyl-CoA desaturase-1 is a key factor for lung cancer-initiating cells. Cell Death Dis 4: e947, 2013.

29. Mason P, Liang B, Li L, Fremgen T, Murphy E, Quinn A, Madden SL, Biemann HP, Wang B, Cohen A, et al: SCD1 inhibition causes cancer cell death by depleting mono-unsaturated fatty acids. PLoS One 7: e33823, 2012.

30. Hess D, Chisholm JW and Igal RA: Inhibition of stearoylCoA desaturase activity blocks cell cycle progression and induces programmed cell death in lung cancer cells. PLoS One 5: e11394, 2010.

31. Kleene KC: Y-box proteins combine versatile cold shock domains and arginine-rich motifs (ARMs) for pleiotropic functions in RNA biology. Biochem J 475: 2769-2784, 2018.

32. Lyons SM, Achorn C, Kedersha NL, Anderson PJ and Ivanov P: YB-1 regulates tiRNA-induced stress granule formation but not translational repression. Nucleic Acids Res 44: 6949-6960, 2016.

33. Somasekharan SP, El-Naggar A, Leprivier G, Cheng H, Hajee S, Grunewald TGP, Zhang F, Ng T, Delattre O, Evdokimova V, et al: YB-1 regulates stress granule formation and tumor progression by translationally activating G3BP1. J Cell Biol 208: 913-929, 2015.

34. Willis WL, Hariharan S, David JJ and Strauch AR: Transglutaminase-2 mediates calcium-regulated crosslinking of the Y-Box 1 (YB-1) translation-regulatory protein in TGF $\beta 1$-activated myofibroblasts. J Cell Biochem 114: 2753-2769, 2013.

35. Zhang A, Liu X, Cogan JG, Fuerst MD, Polikandriotis JA, Kelm RJ Jr and Strauch AR: YB-1 coordinates vascular smooth muscle $\alpha$-actin gene activation by transforming growth factor $\beta 1$ and thrombin during differentiation of human pulmonary myofibroblasts. Mol Biol Cell 16: 4931-4940, 2005 
36. Miao X, Wu Y, Wang Y, Zhu X, Yin H, He Y, Li C, Liu Y, Lu X Chen Y, et al: Y-box-binding protein-1 (YB-1) promotes cell proliferation, adhesion and drug resistance in diffuse large B-cell lymphoma. Exp Cell Res 346: 157-166, 2016.

37. Heumann A, Kaya Ö, Burdelski C, Hube-Magg C, Kluth M, Lang DS, Simon R, Beyer B, Thederan I, Sauter G, et al: Up regulation and nuclear translocation of Y-box binding protein 1 (YB-1) is linked to poor prognosis in ERG-negative prostate cancer. Sci Rep 7: 2056, 2017

38. Ha B, Lee EB, Cui J, Kim Y and Jang HH: YB-1 overexpression promotes a TGF- $\beta 1$-induced epithelial-mesenchymal transition via Akt activation. Biochem Biophys Res Commun 458: 347-351, 2015.

39. Wu SL, Fu X, Huang J, Jia TT, Zong FY, Mu SR, Zhu H, Yan Y, Qiu S, Wu Q, et al: Genome-wide analysis of YB-1-RNA interactions reveals a novel role of YB-1 in miRNA processing in glioblastoma multiforme. Nucleic Acids Res 43: 8516-8528, 2015.

40. Wei WJ, Mu SR, Heiner M, Fu X, Cao LJ, Gong XF, Bindereif A and Hui J: YB-1 binds to CAUC motifs and stimulates exon inclusion by enhancing the recruitment of U2AF to weak polypyrimidine tracts. Nucleic Acids Res 40: 8622-8636, 2012.

41. Dolfini D and Mantovani R: Targeting the Y/CCAAT box in cancer: YB-1 (YBX1) or NF-Y. Cell Death Differ 20: 676-685, 2013.

42. Livak KJ and Schmittgen TD: Analysis of relative gene expression data using real-time quantitative PCR and the 2(-Delta Delta C(T)) method. Methods 25: 402-408, 2001

43. Shurtleff MJ, Temoche-Diaz MM, Karfilis KV, Ri S and Schekman R: Y-box protein 1 is required to sort microRNAs into exosomes in cells and in a cell-free reaction. Elife 5: e19276, 2016.

44. Peter A, Weigert C, Staiger H, Rittig K, Cegan A, Lutz P, Machicao F, Häring HU and Schleicher E: Induction of stearoyl-CoA desaturase protects human arterial endothelial cells against lipotoxicity. Am J Physiol Endocrinol Metab 295: E339-E349, 2008.

45. Yuan Z, Shin J, Wilson A, Goel S, Ling YH, Ahmed N, Dopeso H, Jhawer M, Nasser S, Montagna C, et al: An A13 repeat within the 3'-untranslated region of epidermal growth factor receptor (EGFR) is frequently mutated in microsatellite instability colon cancers and is associated with increased EGFR expression. Cancer Res 69: 7811-7818, 2009.
46. KhanA,Fornes O,Stigliani A,GheorgheM,Castro-MondragonJA, van der Lee R, Bessy A, Chèneby $\mathrm{J}$, Kulkarni SR, Tan G, et al: JASPAR 2018: Update of the open-access database of transcription factor binding profiles and its web framework. Nucleic Acids Res 46: D260-D266, 2018.

47. Li J, Lu Y, Akbani R, Ju Z, Roebuck PL, Liu W, Yang JY, Broom BM, Verhaak RGW, Kane DW, et al: TCPA: A resource for cancer functional proteomics data. Nat Methods 10: 1046-1047, 2013

48. Pisanu ME, Noto A, De Vitis C, Morrone S, Scognamiglio G, Botti G, Venuta F, Diso D, Jakopin Z, Padula F, et al: Blockade of Stearoyl-CoA-desaturase 1 activity reverts resistance to cisplatin in lung cancer stem cells. Cancer Lett 406: 93-104, 2017.

49. Horikawa M, Nomura $T$, Hashimoto $T$ and Sakamoto $K$ : Elongation and desaturation of fatty acids are critical in growth, lipid metabolism and ontogeny of caenorhabditis elegans. J Biochem 144: 149-158, 2008.

50. von Roemeling CA, Marlow LA, Wei JJ, Cooper SJ, Caulfield TR, Wu K, Tan WW, Tun HW and Copland JA: Stearoyl-CoA desaturase 1 is a novel molecular therapeutic target for clear cell renal cell carcinoma. Clin Cancer Res 19: 2368-2380, 2013.

51. Zhang H, Li H, Ho N, Li D and Li S: Scd1 plays a tumor-suppressive role in survival of leukemia stem cells and the development of chronic myeloid leukemia. Mol Cell Biol 32: 1776-1787, 2012. International (CC BY-NC-ND 4.0) License. 